\title{
Article \\ E-Commerce and the Factors Affecting Its Development in the Age of Digital Technology: Empirical Evidence at EU-27 Level
}

\author{
Roxana Maria Bădîrcea ${ }^{1, * \mathbb{D}}$, Alina Georgiana Manta ${ }^{1} \mathbb{D}$, Nicoleta Mihaela Florea ${ }^{1}$, Jenica Popescu ${ }^{1}$, \\ Florin Liviu Manta ${ }^{2}$ (D) and Silvia Puiu ${ }^{3}$ (D)
}

1 Department of Finance, Banking and Economic Analysis, Faculty of Economics and Business Administration, University of Craiova, 13 A.I. Cuza, 200585 Craiova, Romania; alina.manta@edu.ucv.ro (A.G.M.); nicoleta.florea@edu.ucv.ro (N.M.F.); jenica.popescu@edu.ucv.ro (J.P.)

2 Mechatronics and Robotics Department, University of Craiova, 200585 Craiova, Romania; florin.manta@edu.ucv.ro

3 Department of Management, Marketing and Business Administration, Faculty of Economics and Business Administration, University of Craiova, 13 A.I. Cuza, 200585 Craiova, Romania; silviapuiu@yahoo.com

* Correspondence: roxana.badircea@edu.ucv.ro

check for updates

Citation: Bădîrcea, R.M.; Manta, A.G.; Florea, N.M.; Popescu, J.; Manta, F.L.; Puiu, S. E-Commerce and the Factors Affecting Its Development in the Age of Digital Technology: Empirical Evidence at EU-27 Level. Sustainability 2022, 14, 101. https://doi.org/10.3390/ su14010101

Academic Editors: Dan-Cristian Dabija, Catalina Soriana Sitnikov, Anca Bandoi, Dana Danciulescu and Cristinel Vasiliu

Received: 19 November 2021 Accepted: 18 December 2021 Published: 23 December 2021

Publisher's Note: MDPI stays neutral with regard to jurisdictional claims in published maps and institutional affiliations.

Copyright: (c) 2021 by the authors. Licensee MDPI, Basel, Switzerland. This article is an open access article distributed under the terms and conditions of the Creative Commons Attribution (CC BY) license (https:// creativecommons.org/licenses/by/ $4.0 /)$.

\begin{abstract}
The purpose of this study is to identify the factors influencing e-commerce and to evaluate the long and short-term impacts on the development of e-commerce activity. After establishing the hypotheses to verify, we use multiple panel regressions to test the influence of education level, consumer's residence, consumer's labour market status, internet banking, mobile and non-mobile users on the development of e-commerce. For this matter, in this paper, by adopting the fully modified ordinary least squares (FMOLS) method and a vector error correction model (VECM), we performed an empirical analysis of the nexus between education level, consumer's residence, consumer's labour market status, internet banking and mobile and non-mobile users and e-commerce, based on panel data for EU-27 countries from 2011 to 2020. The results of the study indicate that all the variables involved in the two econometric models and associated with education level, consumer's residence, labour market status, internet banking, mobile and non-mobile users, all have significant impacts on the development of e-commerce. Most of the variables positively influence the development of e-commerce except for internet purchases by individuals un-employed and for internet purchases by non-mobile users that are negatively correlated with e-commerce activity.
\end{abstract}

Keywords: education; residence; labour market status; internet banking; mobile users; panel data; fully modified ordinary least squares; positive correlations

\section{Introduction}

Advances in recent decades in the field of technology, but especially of computers and the Internet have led to an impact on society and the emergence of disparities in this regard both nationally and, especially, globally [1].

This expansion has led to faster, safer and more efficient businesses with beneficial effects for both producers and consumers. E-commerce represented overcoming the simple exchange of products and services for money and the orientation towards the exchange of information between organizations and their customers [2]. Thus, the development of wireless technology and telephony networks led to the development and expansion of the field of e-commerce to mobile e-commerce (m-commerce) as "mobile applications (mobile Apps) have changed the ecosystem of the business world" [3].

All definitions of mobile e-commerce $[4,5]$ agree that it is a platform that allows customers with mobile devices to access banking services and other commercial facilities through them and thus "we are now facing a process of digital transformation transition to digitalization in nearly all the services of our globalized economy" [6]. The main areas of use of mobile commerce are texting, telephone payments, financial and banking services, purchases and sales of products and services, etc. 
Using mobile devices for commerce not only means paying with your mobile device in physical stores, but also involves m-commerce, shopping for products (and paying for these purchases) on that mobile device. Regardless of the development that $\mathrm{m}$-commerce has known and will experience, shopping habits will remain mixed between store, e-commerce and $\mathrm{m}$-commerce for a long time. Although at first glance the success and advantages of mobile e-commerce seem immediate, in reality the successful implementation is not very simple and differs depending on several aspects such as money, technology and people [6].

The number of internet users in Europe has seen a growth of 539\% between 2000 and 2021, with the number of internet users now at 728 million, representing $14.4 \%$ of the total number of internet users worldwide, ranking second after. Regarding the internet penetration rate in Europe, it is $87.1 \%$, second after that of North America at $89.9 \%$, but higher than Asia, where it is 62.2\% [7].

According to European reports [8], across Europe, the use of e-commerce is increasing as the number and share of e-buyers rises every year. The biggest jump for e-shoppers can be seen in 2020, in part because of the COVID-19 pandemic that is inducing consumers to shop online. Furthermore, according to other study [9], the most developed countries from the e-commerce perspective are Ireland, Belgium and the Czech Republic. These countries have been able to exploit the potential of e-commerce due to structural and policy changes at the government level, establishing a positive environment for companies involved in e-commerce. Moreover, other authors [10] pointed out that some countries could not implement e-commerce effectively due to lack of trust and confidence of customers in online transactions and weak laws and regulations to protect them.

The existence of large differences in internet access and e-commerce use between developed and developing countries led us to analyse the factors influencing the use and success of e-commerce in European Union countries, with a focus on the relationship between internet banking and e-commerce. One of the aims of this study is to evaluate whether the socio-economic characteristics of buyers-such as education, residence, and income-affect e-commerce. The second aim of the study is to analyse e-commerce from the perspective of mobile payment, internet banking - trend towards mobile e-commerce. These aims will be fulfilled using four hypotheses that will be further described in the following sections. The overall understanding of these features of the consumers under the e-commerce environment is still missing in the recent literature, and this study conducts an empirical study to close the gap.

Thus, the article is organized as follows: The following section presents the literature review and the development of the hypotheses. The third section emphasizes the econometric model and methods used. The following sections describe the results and implications for the discussions. The final part is allocated to the conclusions of the study.

\section{Review of the Scientific Literature}

According to Mukhopadhyay, identifying the factors that influence the success of e-commerce has been considered difficult [11] due to a limited conceptual basis.

\subsection{E-Commerce from the Perspective of Consumer's Education Level}

A study [12] based on a survey of university students in England about their attitudes and behaviours towards consumer education, student identity and academic performance revealed that the consumer orientation was associated with a lower academic performance.

Mitiko [13] noted, using a questionnaire applied to 271 consumers on 10 product types, that the perception of a particular product type may differ depending on the level of education.

An important factor influencing consumer behaviour and decision-making is education, as it allows the consumer to adapt to the requirements of the new era of technological change. Education allows the assimilation of new knowledge throughout life that allows adaptation to the accelerated pace of technological innovation and increases the ability of consumers to decide [14]. 
Contrary to the conclusions of most articles, Mbah et al. [15] noted that in Nigeria, education has no significant effect on the behaviour of online shoppers.

Beneke, Scheffer, and Du [16], exploring the factors that drive customers to shop online, concluded that demographic variables such as income, education, and age can have a significant effect on buying intention. They also analysed which categories of goods are frequently bought on the internet and what sellers can do to ensure easy access for buyers.

Lack of training and education have been identified as barriers to the adoption of new technologies, so education is an important factor in analysing consumer behaviour [17]. Closely related to education, Foster [18] found that there is a trend towards more educated and informed consumers, with different spending patterns. At the same time, the cost of education tends to increase, influencing the way consumers spend their money on products such as clothing, food and furniture.

According to the Eurostat Regional Yearbook [19], "less than half of all EU regions have reached the policy target for tertiary educational attainment". Moreover, as stated also by Eurostat in E-commerce Statistics [20], "the proportion of internet users having a higher level of education shopping online is 33 percentage points higher than that of internet users with lower education".

Therefore, the following hypothesis is postulated:

Hypothesis 1 (H1). There is a significant relationship between e-commerce and education level.

\subsection{E-Commerce from the Perspective of Consumer's Residence}

Jing et al. [21] pointed out that the impact of internet funding on the consumption of urban residents is greater than that of rural residents. That is why they consider it necessary to promote the financial use of the internet in rural areas in order to expand the consumption demand of the rural population and thus ensure the balanced development of the urban and rural environment.

It has been found that regional migration leads to a fragmentation of the consumer base [22]. Different objectives must be considered-race and ethnicity, urban vs. rural and geographical origin-together, to analyse consumers, so it is increasingly clear that the consumer cannot be thought of in simple and generalized ways. The consumer must be looked at through a kaleidoscope of factors to create the most complete picture of the dynamic consumer.

There are studies that have shown that the involvement of people in rural areas in e-commerce activities leads to the eradication of poverty, can create a path to inclusive growth and also represent a leap in the paradigm of knowledge [23,24].

Blasio [25] analysed the importance of coming from urban or rural areas it comes to the use of internet, e-commerce and e-banking in Italy. He noted that the use of the internet is much more common among urban consumers than among the non-urban ones, and the use of e-commerce is basically unaltered by the size of the city. Free-time activities and cultural items are the only goods and services for the care of e-commerce that are used more in isolated areas. Finally, e-banking has nothing to do with the size of the city, and non-urban customers place more importance on personal knowledge than urban customers do.

As for the situation at the EU-27 level, as stated in the Eurostat Regional Yearbook [19], on one hand, in "some parts of the EU, the geographical distribution of cities follows a pattern of close proximity". On the other hand, other parts "are characterised by a more sparse distribution of cities over a much major area". Therefore, this specific EU-27 spatial distribution of cities and rural areas could influence the development of e-commerce accordingly.

Starting from the information from these works, we formulated the following hypothesis:

Hypothesis 2 (H2). There is a significant relationship between e-commerce and residence. 


\subsection{E-Commerce from the Perspective of Consumer's Labour Market Status}

Employees have the largest share and play a very important part in shaping the future in all countries and in adopting ultimate technologies, generating effects on several sectors, such as trade, industry, services, etc [26]. Most articles deal with the effects that e-commerce generates on the labour market, in the sense that activities involving modern technologies affect workers who have failed to acquire the skills needed to use modern technologies [27-29].

According to the Eurostat Regional Yearbook [19], "the EU-27 employment rate was 73\% in 2019-the highest rate since the beginning of the time series". On the other hand, Eurostat indicators [20] emphasize that "some EU Member States continued to experience considerable regional disparities in the unemployment rate". Some of the regions face structural problems, while others have not yet been fully recovered from the international financial and economic crisis. Moreover, according to Eurostat (Eurostat, 2020), "employees and the self-employed ( $78 \%$ of internet users) as well as students $(77 \%)$ shop online far more than unemployed (61\%) or retired/inactive people $(55 \%)^{\prime \prime}$.

However, we did not identify papers that analyse the extent to which the unemployed people together with employees are involved in e-commerce, so we identified the following hypothesis of our study:

Hypothesis 3 (H3). There is a Significant Relationship between E-Commerce and Labour Market Status.

Most studies that focus on how education level, residence and labour market status influence consumer behaviour are based on data obtained from questionnaires and very few studies are based on data obtained from national or international statistics. Therefore, in this paper, we aimed to see if the results obtained by empirical analysis of data from international and regional statistics will lead to results similar to those of the works that processed the data obtained on the basis of questionnaires.

\subsection{E-Commerce from the Perspective of Mobile Payment, Internet Banking-Trend towards Mobile E-Commerce}

Khodawindi [30] concluded that mobile payment plays a key part in the acceptance and increasing of m-commerce by not only providing a convenient, simple and secured payment method, but also its services are not only for the m-commerce segment, but its scope being also larger. However, mobile payments provide a vital basis for $\mathrm{m}$-commerce infrastructure and should therefore be considered a component of mobile business. In the same context, Lee et al. [31] stated that m-banking applications are an innovation that could become one of m-commerce's value-added applications. Tiwari and Buse [32] believe that the future of mobile banking and m-commerce is intertwined in many ways and that mobile banking will play a major role in the future development of m-commerce.

We emphasize the above-mentioned study [30] that analysed the viability of mobile payment services and that confirmed the widespread acceptability of such methods among consumers. In a chapter examining the implications of e-commerce on banks, Heng [33] believes that banks and financial institutions must contribute to e-business and behave like true institutional innovators.

Many studies have found that there is a huge market potential for mobile applications based on the penetration rate of mobile devices [34-38]. Other researchers [39] argue that the popularity of $\mathrm{m}$-commerce cannot be correlated with the popularity of mobile devices because $\mathrm{m}$-commerce goes beyond mobile telephony. It is considered that mobile devices with wireless internet connections should be seen as a precondition for e-commerce.

A paper [40] on assessing and analysing consumer perceptions and behavioural intentions in the field of $\mathrm{m}$-commerce highlighted the importance that sellers should place on smartphones as an additional tool to ensure sales growth. The ability of mobile devices to access the internet more easily and at a lower price compared to internet services on 
a desktop computer, which requires greater hardware investments and computer skills, means that mobile phones have huge growth potential in terms of the global volume of e-commerce [36-38]. Thus, m-commerce applications appear to be easier to use than desktop-based ones due to the familiarization of consumers with mobile devices [40]. Given that desktop computers are mostly used for accessing the internet, some potential buyers on the internet are excluded, namely those who do not have daily access to a PC, those who do not have the skills to use PCs and those who cannot afford to purchase a PC.

Daitch et al. [38] consider that in terms of wireless internet access, transactions and applications made with mobile phones will far exceed those made on PCs.

Regarding the importance of mobile money, Veniard [41] considers that they responded to a shortage and "changed the economy of small accounts". The adoption of mobile money provides citizens with a secure means of transfer and payment at a lower cost, but also secure and private storage of funds. On the other hand, Vilasenor [42] identifies several ways to maximize financial and digital inclusion using mobile technologies. Internet banking significantly reduces banks' operating costs and increases customer satisfaction and represents a way to build customer loyalty. At the same time, internet banking has a strategic role to play in the banking sector of emerging economies [43].

However, statistics from international authorities at the European level [44] reveal the fact that at least $69 \%$ of households have access to broadband in each European region, and over $90 \%$ of households are fully connected in most regions. This demonstrates remarkable progress over the last decade in reducing gaps in access to digital infrastructure. But convergence between regions in the use of digital services has been slow. Even today, in many parts of South-Eastern Europe, Southern Italy and parts of Portugal, less than a third of the population uses the internet to order goods or services, unlike Belgium, Germany, the Netherlands, the United Kingdom or Scandinavia, where three quarters of the population shop online [44].

This leads to the development of the following hypothesis:

Hypothesis 4 (H4). There is a significant relationship between e-commerce, internet banking and mobile users.

From the hypotheses mentioned above, it is reasonable to investigate the factors influencing e-commerce and to evaluate the long and short-term impacts on the development of e-commerce activity. Thus, we ask the next research question:

Research Question. To what extent is e-commerce activity influenced by different factors, and which are the most significant ones across the EU-27 countries?

In order to achieve our objective, we ran a panel regression for EU-27 countries over the 2011-2020 period to examine the influence of education level, consumer residence, consumer labour market status, internet banking, mobile and non-mobile users on the development of e-commerce. Therefore, we find clear evidence that education level, consumer residence, labour market status, internet banking, mobile and non-mobile users all have significant effects on the development of e-commerce.

\section{Research Methodology}

Based on our analysis, in order to assess the four hypotheses, we use multiple panel regressions to test the influence of these different factors, namely education level, consumer's residence, consumer's labour market status, internet banking, mobile and non-mobile users on the development of e-commerce. For this mater, in this paper, by adopting the fully modified ordinary least squares (FMOLS) method and a vector error correction model (VECM), we performed an empirical analysis of the nexus between education level, consumer's residence, consumer's labour market status, internet banking, and mobile users and e-commerce, based on panel data for EU-27 countries from 2011 to 2020. 
We selected panel data for EU-27 countries, and the European average (from 2020) was also taken into consideration during 2011-2020 as samples, except for the H4, where the data for the variables mobile users and non-mobile users were available only for the 2013-2019 period. All data were collected from the Eurostat Database [45].

In order to verify the first three hypotheses, we design a basic econometric model developing the equation proposed by He and Richard [46]:

$$
\begin{aligned}
& \ln E C O M_{i t}=\alpha_{1}+\alpha_{2} \ln H I G H E D_{i t}+\alpha_{3} \ln M E D E D_{i t}+\alpha_{4} \ln L O W E D_{i t}+\alpha_{5} \ln \text { CITIES }_{i t} \\
& +\alpha_{6} \ln T O W N S_{i t}+\alpha_{7} \ln R U R A L_{i t}+\alpha_{8} \ln E M P L_{i t}+\alpha_{9} \ln S T U D_{i t}+\alpha_{10} \ln U N E M P L_{i t}+\mu_{\alpha i t}
\end{aligned}
$$

where:

$\ln E C O M$-natural logarithm of the internet purchases by individuals (e-commerce); $\ln H I G H E D$ - natural logarithm of internet purchases by individuals with high formal education;

$\ln M E D E D$ — natural logarithm of internet purchases by individuals with medium formal education;

$\ln L O W E D$ - natural logarithm of internet purchases by individuals with low formal education;

$\operatorname{lnCITIES}$ - natural logarithm of internet purchases by individuals living in cities;

$\ln$ TOWNS - natural logarithm of internet purchases by individuals living in towns and suburbs;

$\ln R U R A L$ - natural logarithm of internet purchases by individuals living in rural areas;

$\ln E M P L$ - natural logarithm of internet purchases by employees;

lnSTUD - natural logarithm of internet purchases by students;

$\ln U N E M P L$ - natural logarithm of internet purchases by unemployed people;

$\alpha(1, \ldots, 10)$ — coefficients linked to the variables;

$\mu \alpha$ it - the residual term;

$i$-the country and;

$t$-the time period.

To verify $\mathrm{H} 4$, evaluating the impact of internet banking and mobile users on the development of e-commerce, as the time period is different from the others, we developed the following equation based on the one proposed by He and Richard [46]:

$$
\ln E C O M_{i t}=\beta_{1}+\beta_{2} \ln E B A N K_{i t}+\beta_{3} \ln M O B U S_{i t}+\beta_{4} \ln N O M O B U S_{i t}+\mu_{\text {it }}
$$

where:

$\ln E C O M$-natural logarithm of the internet purchases by individuals (e-commerce); $\ln E B A N K$ - natural logarithm of internet purchases by individuals using internet banking; $\ln M O B U S$ - natural logarithm of internet purchases by individuals-mobile internet users; lnNOMOBUS - natural logarithm of internet purchases by individuals-non-users of mobile internet;

$\beta(1, \ldots, 4)$-coefficients associated to the variables;

$\mu \beta$ it- the residual term;

$i$-the country;

$t$ - the time period.

Furthermore, the first stage in estimating the causality nexus between the variables comprised in the models above is to assess the stationary of the data series used. Therefore, a test was conducted by applying Levin-Lin-Chu [47] panel root tests and ADF-Fisher Chi-square and PP-Fisher Chi-square tests suitable for panel data. The second stage implies performing the Kao [48] specific panel data test for evaluating if there is a co-integration nexus between the selected variables for each model corresponding to the four hypotheses presented in the previous section.

After having identified a long-term co-integration nexus in the proposed models, FMOLS is used for evaluating the elasticity of the e-commerce to the selected variables. Using the panel, FMOLS implies many advantages. It allows for serial correlation, the exis- 
tence of endogeneity, and cross-sectional heterogeneity. Thus, pooled FMOLS estimation described by Pedroni [49] is used for heterogeneity through cross-sectional-specific estimates of long-run covariances in order to reweight the data before computing the pooled FMOLS. Therefore, we use the estimator designed by Phillips and Hansen [50] which applies a semi-parametric correction to eliminate the obstacles entailed by the long-term correlations between the co-integrating equations and the stochastic regressor innovations.

In the case of a co-integration between the variables, VECM is applied to identify the short-term and long-term causality nexus and to evaluate the co-integration link embedded in the specifications. The co-integration term is called the error correction term (ECT).

\section{Results and Discussion}

\subsection{Results}

The descriptive statistical analysis of variables is presented in Table 1 . Table 1 shows that the data corresponding to the variables have large divergences. In order to eliminate the heteroscedasticity effect, the variables are transformed in logarithmic in all the models corresponding to the four hypotheses.

Table 1. Variable definition and descriptive statistics.

\begin{tabular}{ccccccc}
\hline & Definition & Mean & Maximum & Minimum & Std. Dev. & Observations \\
\hline ECOM & E-commerce & 37.66 & 79 & 3 & 18.20 & 280 \\
HIGHED & High education & 55.73 & 89 & 11 & 18.65 & 280 \\
MEDED & Medium education & 37.40 & 80 & 2 & 19.02 & 280 \\
LOWED & Lower education & 22.10 & 69 & 0 & 16.03 & 280 \\
CITIES & Cities & 40.98 & 83 & 5 & 18.05 & 280 \\
TOWNS & Towns & 37.37 & 81 & 2 & 18.10 & 280 \\
RURAL & Rural areas & 34.13 & 76 & 1 & 18.78 & 280 \\
EMPL & Employees & 45.67 & 84 & 4 & 19.83 & 280 \\
STUD & Students & 47.23 & 86 & 6 & 17.81 & 280 \\
UNEMPL & Unemployed & 30.18 & 83 & 2 & 17.42 & 280 \\
EBANK & E-banking & 49.88 & 91 & 4 & 22.88 & 196 \\
MOBUS & Mobile users & 53.19 & 81 & 16 & 15.58 & 196 \\
\hline
\end{tabular}

Furthermore, we examine below the influences of the selected variables on the ecommerce in the models proposed in the previous section by applying first all the specific panel data tests in order to enhance the reliability of the obtained results. Afterwards, the estimation results of each econometric model by using FMOLS and VECM are shown separately corresponding to the four described hypotheses.

4.1.1. Nexus between E-Commerce, Consumer's Education Level, Residence and Labour Market Status

In order to estimate the impact of the education level, residence and labour market status on the e-commerce development, the panel data used are tested by applying the panel unit root tests. Table 2 emphasizes that the panel test results performed at first difference for all variables passed the significance test at the $1 \%$ level, thus indicating that the first differences of the variables are stationary. Furthermore, we will proceed to testing the econometric models applying the tests and using the estimators FMOLS and VECM.

According to the results above, as all the variables are stationary at first difference because $\mathrm{p}$-value is below 0.05 , the Kao co-integration test is further performed with the results in Table 3.

Thus, the results of Kao co-integration test from Table 3 point out that there is a long-term relationship between the variables.

Therefore, at least one cointegration nexus is found between the variables of the model. A second cointegration test (Johansen Fisher Panel Cointegration Test) is applied. Once more, the results from Table 4 emphasize the existence of at least one cointegration relationship among the variables. 
Table 2. LLC unit root test, ADF-Fisher Chi-square and PP-Fisher Chi-square test results at level and at first difference for the variables in EU-27 countries.

\begin{tabular}{cccc}
\hline Methods & Statistic $(p)$ in LLC & Statistic $(p)$ in ADF & Statistic $(p)$ in PP \\
\hline $\ln E C O M$ & $-3.6124(0.0002)$ & $28.009(0.9994)$ & $61.6871(0.2800)$ \\
dlnECOM & $-7.1350(0.0000)$ & $109.928(0.0000)$ & $235.459(0.0000)$ \\
$\ln H I G H E D$ & $-2.5848(0.0049)$ & $25.0057(0.9999)$ & $97.1086(0.0005)$ \\
dlnHIGHED & $-12.135(0.0000)$ & $130.681(0.0000)$ & $289.186(0.0000)$ \\
$\ln M E D E D$ & $-4.4850(0.0000)$ & $36.8671(0.9774)$ & $60.4102(0.3196)$ \\
dlnMEDED & $-8.1093(0.0000)$ & $122.312(0.0000)$ & $263.835(0.0000)$ \\
$\ln L O W E D$ & $0.1249(0.5497)$ & $21.4790(1.0000)$ & $36.8897(0.9773)$ \\
dlnLOWED & $-10.574(0.0000)$ & $118.644(0.0000)$ & $220.718(0.0000)$ \\
$\ln$ CITIES & $0.8756(0.1906)$ & $21.1250(1.0000)$ & $61.0428(0.2996)$ \\
dlnCITIES & $-10.196(0.0000)$ & $137.309(0.0000)$ & $285.600(0.0000)$ \\
$\ln T O W N S$ & $-9.2106(0.0000)$ & $57.9177(0.4044)$ & $79.6780(0.0205)$ \\
dlnTOWNS & $-7.7210(0.0000)$ & $127.264(0.0000)$ & $248.589(0.0000)$ \\
$\ln$ RURAL & $-4.9739(0.0000)$ & $42.9659(0.8994)$ & $67.6961(0.1360)$ \\
dlnRURAL & $-13.491(0.0000)$ & $129.548(0.0000)$ & $242.642(0.0000)$ \\
$\ln E M P L$ & $-3.4506(0.0003)$ & $28.3586(0.9992)$ & $67.5277(0.1391)$ \\
dlnEMPL & $-5.7303(0.0000)$ & $105.058(0.0001)$ & $247.560(0.0000)$ \\
$\ln S T U D$ & $-9.5506(0.0000)$ & $78.7408(0.0242)$ & $88.1016(0.0040)$ \\
dlnSTUD & $-11.816(0.0000)$ & $130.307(0.0000)$ & $255.867(0.0000)$ \\
$\ln U N E M P L$ & $-1.8285(0.0337)$ & $34.9084(0.9879)$ & $62.1065(0.2677)$ \\
dlnUNEMPL & $-15.391(0.0000)$ & $131.816(0.0000)$ & $287.170(0.0000)$
\end{tabular}

Note: $\ln E C O M$ is natural logarithm of the internet purchases by individuals (e-commerce), $\ln H I G H E D$ is natural logarithm of internet purchases by individuals with high formal education, $\ln M E D E D$ is natural logarithm of internet purchases by individuals with medium formal education and $\ln L O W E D$ is natural logarithm of internet purchases by individuals with low formal education, lnCITIES is natural logarithm of internet purchases by individuals living in cities, $\ln T O W N S$ is natural logarithm of internet purchases by individuals living in towns and suburbs and $\ln R U R A L$ is natural logarithm of internet purchases by individuals living in rural areas, $\ln E M P L$ is natural logarithm of internet purchases by employees, lnSTUD is natural logarithm of internet purchases by students and $\ln U N E M P L$ is natural logarithm of internet purchases by unemployed people.

Table 3. Kao co-integration test for the variables in EU-27 countries.

\begin{tabular}{ccc}
\hline & t-Statistic & Prob. \\
\hline ADF & -8.823515 & 0.0000 \\
Residual variance & 0.000613 & \\
HAC variance & 0.000380 & \\
\hline
\end{tabular}

Table 4. Johansen Fisher Panel Cointegration Test.

\begin{tabular}{ccccc}
\hline \multicolumn{4}{c}{ Unrestricted Cointegration Rank Test (Trace and Maximum Eigenvalue) } \\
\hline Hypothesized & Fisher Stat. * & Fisher Stat. * \\
\hline No. of CE(s) & (From Trace Test) & Prob. & (From Max-Eigen Test) & Prob. \\
\hline None & 620.8824 & 0.0000 & 157.4254 & 0.0000 \\
At most 1 & 463.4570 & 0.0001 & 120.4912 & 0.0000 \\
At most 2 & 342.9657 & 0.0000 & 78.05828 & 0.0000 \\
At most 3 & 264.9075 & 0.0000 & 60.37989 & 0.0009 \\
At most 4 & 204.5276 & 0.0000 & 58.07084 & 0.0002 \\
At most 5 & 146.4567 & 0.0000 & 46.17586 & 0.0011 \\
At most 6 & 100.2809 & 0.0000 & 35.15705 & 0.0044 \\
At most 7 & 65.12382 & 0.0000 & 27.32020 & 0.0059 \\
At most 8 & 37.80362 & 0.0000 & 20.62769 & 0.0043 \\
At most 9 & 17.17593 & 0.0000 & 17.17593 & 0.0000 \\
\hline
\end{tabular}

${ }^{*}$ Probabilities are computed using asymptotic Chi-square distribution. Trace test indicates 10 cointegrating eqn(s) at the 0.05 level. Max-eigenvalue test indicates 10 cointegrating eqn(s) at the 0.05 level.

Thus, the long-term cointegration coefficients will be determined using FMOLS in order to examine the elasticity of e-commerce to internet purchases by individuals with 
high formal education, medium formal education and low formal education and present the results in Table 5 .

Table 5. Panel Fully Modified Ordinary Least Squares (FMOLS) Estimation for the variables in EU-27 countries.

\begin{tabular}{ccccc}
\hline Variable & Coefficient & Std. Error & t-Statistic & Prob. \\
\hline $\ln H I G H E D$ & 0.626656 & 0.052922 & 11.84119 & 0.0000 \\
$\ln M E D E D$ & 0.316257 & 0.037760 & 8.375405 & 0.0000 \\
$\ln L O W E D$ & 0.154993 & 0.018476 & 8.388922 & 0.0000 \\
$\ln C I T I E S$ & 0.497745 & 0.023311 & 21.35261 & 0.0000 \\
$\ln T O W N S$ & 0.272803 & 0.021351 & 12.77698 & 0.0000 \\
$\ln R U R A L$ & 0.231453 & 0.020125 & 11.50057 & 0.0000 \\
$\ln E M P L$ & 1.019540 & 0.029102 & 35.03317 & 0.0000 \\
$\ln S T U D$ & 0.139709 & 0.033216 & 4.206089 & 0.0000 \\
$\ln U N E M P L$ & -0.245279 & 0.039131 & -6.268205 & 0.0000
\end{tabular}

Note: $\ln H I G H E D$ is natural logarithm of internet purchases by individuals with high formal education, $\ln M E D E D$ is natural logarithm of internet purchases by individuals with medium formal education and $\ln L O W E D$ is natural logarithm of internet purchases by individuals with low formal education, $\ln$ CITIES is natural logarithm of internet purchases by individuals living in cities, $\ln T O W N S$ is natural logarithm of internet purchases by individuals living in towns and suburbs and $\ln R U R A L$ is natural logarithm of internet purchases by individuals living in rural areas, $\ln E M P L$ is natural logarithm of internet purchases by employees, lnSTUD is natural logarithm of internet purchases by students and lnUNEMPL is natural logarithm of internet purchases by unemployed people.

FMOLS estimation show that over the long term the education level positively impacts the development of e-commerce. Moreover, no matter the education level, the coefficients of internet purchases by individuals with high education, medium education and low education are positive, indicating that the conclusion that education level has a positive effect on e-commerce is robust.

Also, all of the selected variables for this model have a significant impact on the development of e-commerce, as all the corresponding p-values are 0 . Nevertheless, the more highly educated the online consumer, the greater is the effect on the development of e-commerce, as the corresponding coefficients increase from 0.15 in the case of consumers with low education to 0.62 in the case of consumers with high education.

Furthermore, the results show that over the long term, consumer's residence positively affects the development of e-commerce. However, no matter the residence, whether it be cities, towns, or rural areas, there is a significant direct correlation between the e-commerce and the demographic selected variables, the nexus being much more intense in the case of the internet purchases of the individuals living in cities. The estimations from Table 4 point out the fact that the all the long-term nexus between the variables are statistically significant.

In order to identify the short-term nexus between variables, we further apply VECM estimation with the results and corresponding coefficients and probabilities in Table 6 .

As observed in Table 6, in the case of short-term nexus between variables, the results show that the online buying behaviour of the consumers with medium education, consumers living in towns, employed consumers and the online behaviour of students are positively influenced by the development of e-commerce.

However, in the short-term, the internet purchases made by individuals with greater education are negatively influencing the increase of e-commerce activity. This result could emphasize that the cost of education tends to increase, influencing the way consumers spend their money on categories such as clothing, food and furniture. 
Table 6. Coefficients and probabilities associated to the variables in the equations.

\begin{tabular}{|c|c|c|c|c|c|c|c|c|c|c|c|}
\hline & ECT $(-1)$ & $\mathrm{d}(\ln e \operatorname{com}(-1))$ & $\mathrm{d}(\ln h$ ighed $(-1))$ & $\mathrm{d}(\ln$ meded $(-1))$ & $\mathrm{d}(\ln$ lowed $(-1))$ & $\mathrm{d}(\ln$ cities $(-1))$ & $\mathrm{d}(\ln$ towns $(-1))$ & $\mathrm{d}(\ln$ rural $(-1))$ & $\mathrm{d}(\ln e m p l(-1))$ & $\mathrm{d}(\ln s t u d(-1))$ & $\mathrm{d}(\ln u n e m p l(-1))$ \\
\hline $\mathrm{d}($ lnecom) & 0.13 & -0.05 & -0.32 & -0.01 & 0.02 & 0.02 & 0.09 & -0.06 & 0.15 & 0.16 & -0.00 \\
\hline$p$ & $0.01^{* *}$ & 0.85 & $0.02 * *$ & 0.89 & 0.58 & 0.82 & 0.12 & 0.36 & 0.50 & 0.04 ** & 0.96 \\
\hline $\mathrm{d}(\ln$ highed $)$ & 0.07 & -0.08 & -0.64 & 0.08 & -0.00 & 0.08 & 0.01 & -0.09 & 0.44 & 0.18 & 0.00 \\
\hline$p$ & 0.13 & 0.76 & $0.00 *$ & 0.42 & 0.86 & 0.37 & 0.80 & 0.16 & $0.04 * *$ & $0.01 * *$ & 0.95 \\
\hline $\mathrm{d}(\ln$ meded $)$ & 0.17 & 0.36 & -0.48 & -0.41 & 0.00 & 0.05 & 0.17 & 0.02 & 0.12 & 0.15 & 0.01 \\
\hline$p$ & $0.00 *$ & 0.26 & $0.00 *$ & $0.00 *$ & 0.83 & 0.64 & $0.01 * *$ & 0.78 & 0.64 & $0.09 * * *$ & 0.79 \\
\hline $\mathrm{d}(\ln$ lowed $)$ & 0.09 & 1.08 & -0.21 & 0.50 & -0.41 & -0.14 & -0.01 & -0.13 & -0.70 & 0.23 & -0.09 \\
\hline$p$ & 0.36 & $0.05^{* *}$ & 0.43 & $0.01 * *$ & $0.00 *$ & 0.46 & 0.89 & 0.33 & 0.11 & 0.12 & 0.20 \\
\hline $\mathrm{d}($ lncities $)$ & 0.00 & 0.64 & -0.42 & -0.12 & -0.00 & -0.33 & 0.00 & -0.09 & 0.09 & 0.20 & -0.01 \\
\hline$p$ & 0.99 & $0.03^{* *}$ & $0.00 *$ & 0.26 & 0.95 & $0.00 *$ & 0.99 & 0.22 & 0.68 & $0.01 * *$ & 0.76 \\
\hline $\mathrm{d}(\operatorname{lntowns})$ & 0.52 & -0.11 & -0.26 & 0.10 & 0.07 & 0.00 & 0.08 & -0.08 & 0.05 & 0.12 & -0.00 \\
\hline$p$ & $0.00 *$ & 0.72 & $0.09^{* * *}$ & 0.37 & 0.05 & 0.98 & 0.19 & 0.29 & 0.83 & 0.16 & 0.96 \\
\hline $\mathrm{d}(\ln r u r a l)$ & -0.03 & 0.10 & -0.34 & 0.09 & 0.06 & -0.04 & -0.08 & -0.35 & 0.40 & 0.21 & 0.04 \\
\hline$p$ & 0.61 & 0.78 & $0.07^{* * *}$ & 0.52 & 0.22 & 0.73 & 0.32 & $0.00 *$ & 0.19 & $0.04^{* *}$ & 0.40 \\
\hline $\mathrm{d}(\ln e m p l)$ & 0.12 & 0.33 & -0.41 & -0.06 & -0.00 & -0.02 & 0.10 & -0.03 & -0.09 & 0.21 & 0.00 \\
\hline$p$ & $0.01^{* *}$ & 0.22 & 0.00 * & 0.56 & 0.91 & 0.80 & $0.08^{* * *}$ & 0.57 & 0.67 & 0.00 * & 0.95 \\
\hline $\mathrm{d}(\ln s t u d)$ & 0.27 & 0.26 & -0.11 & 0.09 & -0.04 & -0.02 & -0.02 & -0.09 & 0.08 & -0.18 & 0.00 \\
\hline$p$ & $0.00 *$ & 0.44 & 0.52 & 0.46 & 0.29 & 0.87 & 0.70 & 0.29 & 0.74 & $0.05^{* * *}$ & 0.96 \\
\hline $\mathrm{d}(\ln u n e m p l)$ & 0.11 & 0.44 & -0.51 & -0.03 & 0.04 & 0.35 & 0.20 & -0.09 & -0.01 & 0.16 & -0.46 \\
\hline$p$ & 0.25 & 0.39 & $0.04^{* *}$ & 0.84 & 0.50 & $0.06^{* * *}$ & $0.06 * * *$ & 0.47 & 0.97 & 0.25 & $0.00 *$ \\
\hline
\end{tabular}

Note: ${ }^{* *},{ }^{* * *}$ is the significant level of 1,5 or $10 \%$. 


\subsubsection{Nexus between E-Commerce and Internet Banking and Mobile Users}

The last hypothesis to verify is the existence of a significant relationship between e-commerce, internet banking, mobile users and non-mobile users. The results of the tests performed are presented in Tables 7 and 8 . According to the results below, all the variables are stationary at first difference because $p$-value is below 0.05 .

Table 7. LLC unit root test, ADF-Fisher Chi-square and PP-Fisher Chi-square test results at level and at first difference for the variables in EU-27 countries.

\begin{tabular}{cccc}
\hline Methods & Statistic $(p)$ in LLC & Statistic $(p)$ in ADF & Statistic $(p)$ in PP \\
\hline $\ln E C O M$ & $-5.4439(0.0000)$ & $53.2233(0.5806)$ & $81.9450(0.0135)$ \\
d $\ln E C O M$ & $-17.327(0.0000)$ & $136.571(0.0000)$ & $194.929(0.0000)$ \\
$\ln E B A N K$ & $0.2224(0.5880)$ & $20.1104(1.0000)$ & $30.5692(0.9978)$ \\
dlnEBANK & $-16.897(0.0000)$ & $135.177(0.0000)$ & $181.541(0.0000)$ \\
$\ln$ MOBUS & $-9.8026(0.0000)$ & $71.6964(0.0770)$ & $104.740(0.0001)$ \\
dlnMOBUS & $-16.478(0.0000)$ & $119.516(0.0000)$ & $160.256(0.0000)$ \\
$\ln$ NOMOBUS & $-9.2299(0.0000)$ & $83.6758(0.0059)$ & $103.153(0.0001)$ \\
dlnNOMOBUS & $-14.066(0.0000)$ & $116.279(0.0000)$ & $157.871(0.0000)$ \\
\hline
\end{tabular}

Note: $\ln E C O M$ is natural logarithm of the internet purchases by individuals (e-commerce), $\operatorname{lnECOM} —$ natural $\log$ arithm of the internet purchases by individuals (e-commerce); lnEBANK—natural logarithm of internet purchases by individuals using internet banking; $\ln M O B U S$ - natural logarithm of internet purchases by individualsmobile internet users; lnNOMOBUS — natural logarithm of internet purchases by individuals-non-users of mobile internet.

Table 8. Kao co-integration test for the variables in EU-27 countries.

\begin{tabular}{ccc}
\hline & t-Statistic & Prob. \\
\hline ADF & -7.823059 & 0.0000 \\
Residual variance & 0.004530 & \\
HAC variance & 0.004949 & \\
\hline
\end{tabular}

Therefore, at least one cointegration nexus is found between the variables of the model. A second cointegration test (Johansen Fisher Panel Cointegration Test) is applied. Once more, the results from Table 9 emphasize the existence of at least one cointegration relationship among the variables.

Table 9. Johansen Fisher Panel Cointegration Test.

\begin{tabular}{ccccc}
\hline \multicolumn{4}{c}{ Unrestricted Cointegration Rank Test (Trace and Maximum Eigenvalue) } \\
\hline Hypothesized & Fisher Stat. * & Fisher Stat. ${ }^{*}$ \\
\hline No. of CE(s) & (From Trace Test) & Prob. & (From Max-Eigen Test) & Prob. \\
\hline None & 179.2418 & 0.0000 & 122.2479 & 0.0000 \\
At most 1 & 56.99398 & 0.0000 & 32.56918 & 0.0008 \\
At most 2 & 24.42480 & 0.0018 & 22.31547 & 0.0022 \\
At most 3 & 2.109336 & 0.1464 & 2.109336 & 0.1464 \\
\hline
\end{tabular}

${ }^{*}$ Probabilities are computed using asymptotic Chi-square distribution. Trace test indicates three cointegrating eqn(s) at the 0.05 level. Max-eigenvalue test indicates three cointegrating eqn(s) at the 0.05 level.

As the test results are validated, FMOLS is performed, and the results are shown in Table 10. The estimations indicate that internet banking and mobile users are positively influencing e-commerce. However, the internet purchases through mobile banking have a greater impact on e-commerce than the internet purchases through internet banking. This could be correlated to the fact that using mobile banking instead of internet banking is easier and more convenient for most people who are always on the move. 
Table 10. Panel fully modified ordinary least squares (FMOLS) estimation for the variables in EU-27 countries.

\begin{tabular}{ccccc}
\hline Variable & Coefficient & Std. Error & t-Statistic & Prob. \\
\hline $\ln E B A N K$ & 0.606417 & 0.054181 & 11.19243 & 0.0000 \\
$\ln M O B U S$ & 1.168742 & 0.114410 & 10.21542 & 0.0000 \\
$\ln N O M O B U S$ & -0.123300 & 0.048977 & -2.517474 & 0.0130 \\
\hline
\end{tabular}

Furthermore, there is a negative correlation between the internet purchases by nonusers of internet and e-commerce. This result could be interpreted as the fewer non-users of mobile internet, the more improved e-commerce activity because mobile banking is the next level of development for e-commerce and this sector will continue to evolve significantly in the following years.

The results of VECM estimation in Table 11 show that in the short-term the development of e-commerce will contribute to the decrease of internet purchases by individuals using internet banking in favour of individuals using mobile banking.

Table 11. Coefficients and probabilities associated to the variables in the equations.

\begin{tabular}{|c|c|c|c|c|c|}
\hline & ECT(-1) & $\mathrm{d}(\ln \operatorname{ECOM}(-1))$ & $\mathrm{d}(\ln E B A N K(-1))$ & $\mathrm{d}(\ln M O B U S(-1))$ & $\mathrm{d}(\ln N O M O B U S(-1))$ \\
\hline $\mathrm{d}(\ln E C O M)$ & -0.0894 & -0.2757 & -0.0296 & 0.2438 & 0.0328 \\
\hline$p$ & $0.0000 *$ & 0.1156 & 0.7241 & 0.2201 & 0.4949 \\
\hline $\mathrm{d}(\ln E B A N K)$ & -0.1110 & -0.4910 & -0.1545 & 0.3696 & 0.0735 \\
\hline$p$ & $0.0000 *$ & 0.0041 * & $0.0591^{* *}$ & $0.0567 * *$ & 0.1171 \\
\hline $\mathrm{d}(\ln M O B U S)$ & -0.0032 & -0.0611 & 0.0645 & -0.0928 & 0.0486 \\
\hline$p$ & 0.8649 & 0.7206 & 0.4310 & 0.6324 & 0.3008 \\
\hline $\mathrm{d}(\ln N O M O B U S)$ & 0.0515 & 0.4858 & 0.1795 & -0.0349 & -0.3861 \\
\hline$p$ & 0.2296 & 0.2014 & 0.3241 & 0.9354 & $0.0002 *$ \\
\hline
\end{tabular}

Therefore, based on the above results from the two econometric models, the level of education, employment situation, e-banking, mobile and non-mobile users, all significantly affect e-commerce activity. The effects are more consistently seen over the long-term rather than the short-term, with a potential high increase of e-commerce in the following years. Thus, all four assumed hypotheses are verified.

\subsection{Discussions}

Our results prove the clear influence of education level, consumer's residence, consumer's labour market status, internet banking, mobile and non-mobile users on the development of e-commerce.

Moreover, the correlations concerning the level of education could indicate that the improvement of online purchasing channels stimulate the consumers with medium education. Nevertheless, the internet purchases of the individuals with medium education are restrained by the online behaviour of the consumers with high education.

Regarding the influence of consumer residence on the development of e-commerce activity, we obtained some evidence indicating that a high percentage of people living in cities are making purchases online due to many factors, such as good internet infrastructure, accessibility to more information, lack of free time, being all the time on the move, higher income level and more developed internet skills.

On the other hand, the internet purchases of the individuals living in cities is directly correlated with the development of e-commerce. Thus, people living in cities are stimulated to buy more online as the level of e-commerce activity is increasing. Similarly, in order to 
follow the trend and to adapt to the present challenges, people living in rural areas are also positively influenced by the development of e-commerce as they will try to keep up with people living in cities and towns.

However, the internet purchases made by employees and by students are positively influencing the development of e-commerce, while the internet purchases made by unemployed people have a negative impact on the level of e-commerce activity. The better they are positioned in the labour market—employees have a higher income than students- the higher is the influence on e-commerce.

Furthermore, unemployed people are restrained due to financial reasons from having better access and connection to the internet in order to make more online purchases. Therefore, the fewer unemployed, the more developed e-commerce activity will be.

Another influence on e-commerce activity reveals that the internet purchases by individuals using internet banking will develop only if the internet users will become mobile internet users. These results are also supported by the papers mentioned in the Section 2 and also by the actual development of mobile commerce.

The results of this study confirm also the results performed in other studies already mentioned in the description of the hypotheses. Thus, an analysis [51] on the importance of age in the use of information technologies has shown that computer skills are more easily acquired by younger people. Similarly, our study reveals that students are more actively involved and more technologically skilled when it comes to internet purchases because they are positively influencing the development of e-commerce activity.

Similar to another study [16], our results also suggest that an important factor influencing consumer behaviour and decision-making is education, as it allows the consumer to adapt to the requirements of the new era of technological change and the more educated the individual the more the online purchases increase. Furthermore, like Tarafdar and Vaidya [17], we emphasized that lack of training and education are barriers to the adoption of new technologies, so education is an important factor in analysing consumer behaviour. However, similarly with Foster [18], who discovered that the cost of education tends to increase, influencing the way consumers spend their money on categories such as clothing, food and furniture, our short-term results suggested that the internet purchases made by individuals with greater levels of education are negatively influencing the increase of e-commerce activity.

We reached a similar conclusion as De Blasio [25], who analysed the importance of coming from urban or rural areas in the use of the internet, e-commerce and e-banking in Italy. He found that the use of the internet is much more common among urban consumers than among their non-urban counterparts.

Like Tiwari and Buse [32], who believe that the future of mobile banking and mobile commerce is intertwined in many ways and that mobile banking will play a central role in the future development of mobile commerce, the results of our study also emphasize the importance of mobile banking in the future as the next level of development of e-commerce.

Moreover, researchers [52] found that Europe is facing an ever-widening urban-rural divide: people in rural areas are left behind, while urban elites reap the full benefits of globalization and technological change. The fact that poorer areas have grown faster than the richest is a strong indication that rural areas are recovering, as they are on average much poorer than urban areas. The price for the recovery of the countries of Central and Eastern Europe is the increase of the divergence between the urban areas and others.

\section{Conclusions and Recommendations}

The purpose of this study was to identify the factors influencing e-commerce and to evaluate the long- and short-term impacts on the development of e-commerce activity.

After establishing the hypotheses to verify, we used multiple panel regressions to test the influence of these different factors, namely education level, consumer's residence, consumer's labour market status, internet banking, and mobile and non-mobile users on the development of e-commerce. For this matter, in this paper, by adopting the FMOLS method 
and VECM model, we performed an empirical analysis of the nexus between education level, consumer's residence, and consumer's labour market status, internet banking and mobile and non-mobile users and e-commerce based on panel data for EU-27 countries from 2011 to 2020.

The originality of the study is related to the used methodology that is innovative because, as far as we researched, most studies conducted on how education level, residence and labour market status influence consumer behaviour are based on data obtained from questionnaires, which in our view could be very subjective; very few studies are based on data obtained from national or international statistics. Moreover, our analysis is conducted on a large sample of countries while most of the similar studies are made on a single country. Thus, we obtained specific findings related to the different European age groups and level of economic development. Nevertheless, the co-integration tests we performed strongly support our main findings. Furthermore, we did not identify papers that analyse the extent to which the unemployed together with the employed are involved in e-commerce, so we pointed out the impact of labour market status on the development of e-commerce. Also, in this paper, we obtained similar results with those of the authors that processed data obtained on the basis of questionnaires, and also correlated with the statistics presented in Eurostat reports. Therefore, the obtained results are robust and validated through the four described hypotheses.

The results of the study indicate that all the variables involved in the two econometric models and associated with education level, consumer's residence, labour market status, internet banking, mobile and non-mobile users, have significant effects on the development of e-commerce. Most of the variables positively influence the development of e-commerce, except for internet purchases by individuals unemployed and for internet purchases by non-mobile users that are negatively correlated with e-commerce activity. Thus, if increases in internet purchases made by individuals depending on education level, consumer's residence, internet banking and mobile users lead to the improvement of the e-commerce activity, the increasing internet purchases made by unemployed individuals and nonmobile users have a negative impact on e-commerce and will reduce the development of online purchases. The effects are more significant over the long term, with a potential increase in e-commerce activity in the following years.

As for the policy implications and recommendations following the results of this study, we emphasize below the practical implications and the utility of these results.

Nevertheless, Europe has converged in digital infrastructure, but more needs to be done to accelerate the commercial use of digital technologies. Europe has done well in expanding access to broadband [44]. However, in our opinion, more efforts should be made to develop the appropriate infrastructure in rural areas and perhaps a digital education should be implemented.

We agree with the opinions of World Bank's specialists [44], according to whom policymakers can address Europe's digital dilemma by scaling markets, modelling the use of data for commercial use and standardizing technology adoption. In this view, we could emphasize some policy implications.

Firstly, expanding markets would contribute to expanding the use of digital technologies that strengthen market inclusion and convergence.

Secondly, in addressing the new challenges posed by big data in a way that protects European values, updating competition and data privacy policies will strike a balance between competitiveness and inclusion.

Thirdly, accelerating and standardizing the wider deployment and adoption of technologies that tend to focus benefits larger firms, and leading regions will better share the productivity benefits of these technologies.

Concerning the effects of the COVID-19 pandemic, based on the statistics from Eurostat and on our study results, we believe that the increasing trend of internet purchases cannot necessarily be connected with the pandemic but with the general rising trend of digitalization and with the need of people to prioritize personal activities and to adapt 
to the technological innovations. In general, people who prefer to make cash payments are sceptical about the new cashless technologies and they would rather delay as much as possible their transition to making online purchases.

This article used panel data of EU-27 countries to study the impacts of education level, consumer's residence, labour market, e-banking and mobile and non-mobile users on the development of e-commerce. However, there are still some limitations, and more efforts still need to be done. Firstly, concerning the selection of the variables, other control variables could be selected also, like age and gender. Secondly, the data in this study were only provided by Eurostat. Thirdly, in future studies we should highlight the discrepancies between EU countries and extrapolate the research to a worldwide view.

Author Contributions: All six authors equally contributed in designing and writing this paper. Specific tasks were done as follows: Conceptualization, R.M.B. and A.G.M.; Investigation, N.M.F. and J.P.; Methodology, A.G.M. and F.L.M.; Project administration, R.M.B. and A.G.M.; Supervision, A.G.M. and N.M.F.; Writing—review \& editing, A.G.M., F.L.M. and S.P. All authors have read and agreed to the published version of the manuscript.

Funding: This research received no external funding.

Institutional Review Board Statement: Not applicable.

Informed Consent Statement: Not applicable.

Data Availability Statement: Not applicable.

Conflicts of Interest: The authors declare no conflict of interest.

\section{References}

1. Caradaica, M. Digital Divide in the European Union. In Politics and Knowledge: New Trends in Social Research, Proceedings of 7th ACADEMOS Conference 2020 International Conference, Bucharest, Romania, 7-10 October 2020; Filodiritto: Bologna, Italy, 2020.

2. Salami, C.G.E.; Mercy, O. E-Commerce and Banking Performance in Nigeria. J. Inf. Eng. Appl. 2014, 4, 1-18.

3. Al-Adwan, A.S.; Sammou, G. What Makes Consumers Purchase Mobile Apps: Evidence from Jordan. J. Theor. Appl. Electron. Commer. Res. 2021, 16, 562-583. [CrossRef]

4. Mohapatra, S. E-Commerce Strategy; Springer Science+Business Media: Boston, MA, USA, 2013; pp. 81-82.

5. Turban, E.; King, D.; Lee, J.K.; Liang, T.P.; Turban, C.T. Electronic Commerce; Springer International Publishing: Cham, Switzerland, 2015; pp. 7-9.

6. Einav, L.; Levin, J.; Popov, I.; Sundaresan, N. Growth, Adoption and Use of Mobile E-Commerce. Am. Econ. Rev. Pap. Proc. 2014, 104, 489-494. [CrossRef]

7. World Internet Users and Population Stats. Internet Usage Statistics: The Internet Big Picture. 2021. Available online: http: //www.internetworldstats.com/stats.htm (accessed on 3 March 2021).

8. Lone, S.; Harboul, N.; Weltevreden, J. European E-commerce Report; Amsterdam University of Applied Sciences: Amsterdam, The Netherlands; Ecommerce Europe: Brussels, Belgium, 2021; p. 7. Available online: https://ecommerce-europe.eu/wpcontent/uploads/2021/09/2021-European-E-commerce-Report-Light-Version.pdf (accessed on 8 December 2021).

9. Domadenik, P.; Koman, M.; Redek, T. Shaping the Future: Opportunities and Challenges of E-Commerce; Časnik Finance: Ljubljana, Slovenia, 2018; p. 41.

10. Beyari, H. Recent E-Commerce Trends and Learnings for E-Commerce System Development from a Quality Perspective. Int. J. Qual. Res. 2021, 15, 797-810. [CrossRef]

11. Mukhopadhyay, S.; Mahmood, M.A.; Joseph, J.L. Measuring Internet-Commerce Success: What Factors are Important? J. Internet Commer. 2008, 7, 1-28. [CrossRef]

12. Bunce, L.; Baird, A.; Jones, A.S. The student-as-consumer approach in higher education and its effects on academic performance. Stud. High. Educ. 2017, 42, 1958-1978. [CrossRef]

13. Mitiko, D.S.V. Consumers' Education Level Impact on the Perception of the Search Experience Credence Products-Empirical Evidence. J. Internet e-Bus. Stud. 2012, 2012, 8. [CrossRef]

14. Burghelea, C.; Aceleanu, M.I. Education-Determinant Of Consumer's Conditions In An Era Of Technological Change. Amfiteatru Econ. 2014, 16, 535-549.

15. Mbah, C.C.; Odike, M.N.; Akpan, A.O. Effect Of Education On Online Shopping Behaviour In Nigeria. Adv. J. Econ. Mar. Res. 2019, 4, 24-31.

16. Beneke, J.; Scheffer, M.; Du, W. Beyond price-An exploration into the factors that drive young adults to purchase online. Int. J. Mark. Stud. 2010, 2, 212-222. [CrossRef] 
17. Tarafdar, M.; Vaidya, S.D. Challenges in the adoption of E-commerce technologies in India: The role of organizational factors. Int. J. Inf. Manag. 2006, 26, 428-441. [CrossRef]

18. Foster, A.C. New education classification better reflects income and spending patterns in the Consumer Expenditure Survey. In Beyond the Numbers; Bureau of Labor Statistics: Washington, DC, USA, 2014; Volume 3, pp. 1-9.

19. Eurostat. Eurostat Regional Yearbook 2020. Available online: https:/ / ec.europa.eu/eurostat/ (accessed on 2 March 2021).

20. Eurostat. E-Commerce Statistics for Individuals. 2021. Available online: https:/ / ec.europa.eu/eurostat/statistics-explained/ index.php/E-commerce_statistics_for_individuals (accessed on 28 February 2021).

21. Jing, T.; Wengjing, Z.; Yu, D. Correlation with internet Finance and Residence Consumption. Adv. Econ. Bus. Manag. Res. 2017, 42, $25-28$.

22. Lobaugh, K.; Simpson, J.; Stephens, B. The Consumer Is Changing, but Perhaps Not How You Think, Deloitte Insight. 2019 Available online: https://www2.deloitte.com/us/en/insights/industry/retail-distribution/the-consumer-is-changing.html (accessed on 2 March 2021).

23. Rao, S. Bridging the Telecom Divide. Econ. Political Wkly. 2007, 42, 209-211.

24. Anjum, B.; Rajesh Tiwari, C.F.A. Economic and Social Impacts of E-Commerce. Int. J. Comput. Corp. Res. 2011, 1, $208-215$.

25. De Blasio, G. Urban-Rural Differences in internet Usage, e-Commerce, and e-Banking: Evidence from Italy. Growth Chang. 2008, 39, 341-367. [CrossRef]

26. Yang, S.C.; Tung, C.J. Comparison of internet addicts and non-addicts in Taiwanese high school. Comput. Hum. Behav. 2007, 23, 79-96. [CrossRef]

27. Hecker, D.E. Employment impact of electronic business. Mon. Labor Rev. 2001, 124, 3. Available online: https://www.bls.gov/ opub/mlr/2001/05/art1full.pdf (accessed on 2 May 2021).

28. IDEA Consult, Labour Market Analysis in the Commerce Sector: Which Are the Key Challenges and Factors of Change? 2007. Available online: https:/ / uiltucs.it/wp-content/uploads/2015/09/labour-market-in-the-commerce-sector.pdf (accessed on 2 March 2021).

29. OECD. Economic and Social Impact of Ecommerce: Preliminary Findings and Research Agenda; OECD Digital Economy Papers: Paris, France, 1999. [CrossRef]

30. Khodawindi, D.; Pousttchi, K.; Wiedemann, D.G. Akzeptanz mobiler Bezahlverfahren in Deutschland. In Mobile CommerceAnwendungen und Perspektiven, Proceedings zum 3 Workshop Mobile Commerce; Pousttchi, K., Turowski, K., Eds.; Gesellschaft für Informatik e.V.: Bonn, Germany, 2003; pp. 42-57.

31. Lee, M.; McGoldrick, P.J.; Keeling, K.A.; Doherty, J. Using ZMET to explore barriers to the adoption of 3G mobile banking services. Int. J. Retail. Distrib. Manag. 2003, 31, 340-348. [CrossRef]

32. Tiwari, R.; Buse, S. The Mobile Commerce Prospects: A Strategic Analysis of Opportunities in the Banking Sector; Hamburg University Press: Hamburg, Germany, 2007; pp. 47-61.

33. Heng, M.S. Research Note: Implications of E-Commerce for Banking and Finance. U21Global Working 2006, Paper No. 006. Available online: https:/ / ssrn.com/abstract=1614699 (accessed on 28 January 2021).

34. Butler Group, Butler Group Predicts Massive Growth in Mobile Commerce and Responds with Mobile Commerce Portal. 2000 (Press Release). Available online: www.butlergroup.com (accessed on 28 January 2021).

35. Carlsson, C. Mobile Commerce and Value-added Services, The Impact of Intelligent IT; IAMSR Research Report 2000, No.2; Åbo Akademi University: Turku, Finland, 2000.

36. Hampe, J.F.; Swatman, P.M.C.; Swatman, P.A. Mobile Electronic Commerce: Reintermediation in the Payment System. In Proceedings of the 13th Bled International Electronic Commerce Conference, Bled, Slovenia, 19-21 June 2000.

37. Müller-Versee, F. Mobile Commerce Report; Durlacher Research Ltd.: London, UK, 2000.

38. Daitch, J.; Kamath, R.; Kapoor, R.; Nemiccolo, A.; Sahni, S.; Varma, S. Wireless Applications for Business: Business Anytime, Anywhere. Kellogg TechVenture 2000 Anthology. Available online: www.rpi.edu/ \{\}nambis/WirelessApplicationsforBusiness pdf (accessed on 7 February 2021).

39. Vittet-Philippe, P.; Navarro, J.M. Mobile EBusiness (M-Commerce): State of Play and Implications for European Enterprise Policy. European Commission Enterprise Directorate-General E-Business Report, No 3. 2000. Available online: www.ncits.org/tc_home/ v3htm/v301008.pdf (accessed on 10 March 2021).

40. Horga, G.M.; Nica, E.; Nancu, D. Perceptions and behavior-related intentions of consumers in smartphone-based mobile commerce. SHS Web Conf. 2021, 92, 06011. [CrossRef]

41. Veniard, C.; How Agent Banking Changes the Economics of Small Accounts. Brief written for the Global Savings Forum, Bill \& Melinda Gates Foundation, Seattle. Available online: https://docs.gatesfoundation.org/documents/agent-banking.pdf (accessed on 10 March 2021).

42. Villasenor, J. Smartphones for the Unbanked: How Mobile Money Will Drive Digital Inclusion in Developing Countries. The Brookings Institution. Issues Technol. Innov. 2013, 24, 112. Available online: https://www.brookings.edu/research/smartphonesfor-the-unbanked-how-mobile-money-willdrive-digital-inclusion-in-developing-countries/ (accessed on 3 March 2021).

43. Nui Polatoglu, V.; Ekin, S. An empirical investigation of the Turkish consumers' acceptance of internet banking services. Int. J. Bank Mark. 2001, 19, 156-165. [CrossRef]

44. World Bank Group. Europe 4.0. Addressing the Digital Dilemma. 2020. Available online: https:/ /openknowledge.worldbank. org/handle/10986/34746 (accessed on 1 March 2021). 
45. Eurostat. Available online: https:/ / ec.europa.eu/eurostat/data/database (accessed on 28 February 2021).

46. He, J.; Richard, P. Environmental Kuznets curve for $\mathrm{CO}_{2}$ in Canada. Ecol. Econ. 2010, 69, 1083-1093. [CrossRef]

47. Levin, A.; Lin, C.F.; Chu, C. Unit Root Tests in Panel Data: Asymptotic and Finite-Sample Properties. J. Econ. 2002, 108, 1-24. [CrossRef]

48. Kao, C. Spurious regression and residual-based tests for cointegration in panel data. J. Econ. 1999, 90, 1-44. [CrossRef]

49. Pedroni, P. Fully Modified OLS for Heterogeneous Cointegrated Panels; No 2000-03, Department of Economics Working Papers; Williams College: Williamstown, MA, USA, 2000.

50. Phillips, P.; Hansen, B. Statistical Inference in Instrumental Variables Regression with I (1) Processes. Rev. Econ. Stud. 1990, 57, 99-125. [CrossRef]

51. Czara, S.J.; Hammond, K.; Blascovich, J.J.; Swede, H. Age related differences in learning to use a text-editing system. Behav. Inf. Technol. 1989, 8, 309-319.

52. Allianz. Is There Really an Ever-Widening Rural-Urban Divide in Europe? Economic Research. 2019. Available online: https://www.allianz.com/en/press/news/studies/190812_Allianz-Research-EU-rural-urban-income-divide.html (accessed on 4 March 2021). 